\title{
DISPONIBILIDADE, ACESSO E APROPRIAC̣ÃO DA LEITURA NO CONTEXTO DO PROGRAMA "LITERATURA EM MINHA CASA"
}

Maria Jaqueline de Grammont Machado de Araújo*

RESUMO: No presente artigo, a análise centra-se nas práticas leitoras de quatro famílias de grupos periféricos urbanos, da cidade de Belo Horizonte, que receberam livros literários entregues aos alunos do ensino fundamental nos anos de 2001 a 2003 pelo programa "Literatura em minha casa". Utilizando-se de conceitos como disponibilidade, acesso e apropriação, esta análise descortinou diferentes representações de leitor em diferentes comunidades leitoras.

Palavras-chave: Políticas e Práticas de Leitura; Letramento; Leitura.

\section{AVAILABILITY, ACCESS AND APPROPRIATION OF READING IN THE CONTEXT OF THE PROGRAM "LITERATURE AT HOME"}

ABSTRACT: In the present article, we analyzed the reading practices of four families belonging to groups from the urban outskirts of the municipality of Belo Horizonte that received literary books handed to elementary school students from 2001 to 2003, included in the context the reading promotion policies from the program "Literature at home", which used concepts such as availability, access and appropriation.

Keywords: Reading Policies and Practices; Literacy; Reading.

\footnotetext{
*Doutora em Educação pela Universidade Federal Fluminense (UFF) e Professora adjunta da Universidade Federal de São João
} Del-Rei. Email: jaquelinedegrammont@gmail.com 
Este artigo propõe procurar leitores no rastro dos livros de um programa institucional de promoção da leitura que, de forma inusitada, doou livros literários aos alunos da $4^{\mathrm{a}}$ e da $8^{\mathrm{a}}$ séries do ensino fundamental das escolas públicas. Ao seguir esses rastros, o que nos interessa é o encontro entre livros e sujeitos, livros e leitores. Buscou-se, então, dar corpo e voz aos leitores anônimos que, de alguma forma, tiveram acesso ou contato com esses livros.

Meu encontro com os livros desse programa se deu com a chegada deles em minha casa, pelas mãos de um amigo, para as minhas filhas lerem. Como esse amigo conseguira os livros se eles deveriam ter sido entregues diretamente aos alunos? Num primeiro momento, fiquei indignada com a hipótese de esses livros não terem sido entregues aos seus reais destinatários; depois, passei a imaginar o trajeto que eles estariam percorrendo na busca de leitores. Será que eles estavam, ao passar de mão em mão, constituindo uma trilha ou uma rede de leitores? Principalmente, com relação aos livros que foram entregues aos alunos ${ }^{1}$, por quais mãos, olhos e sentidos estariam passando? Que valor teriam nas casas, onde supostamente não há livros nem leitores? Quem seriam aqueles que usufruíam deles nesses grupos? Leitores?

O Programa "Literatura em minha casa"2 diferia de outras políticas ou programas de promoção da leitura por entregar o livro diretamente aos alunos. Se, na perspectiva da política, há uma série de mediadores entre a criança e o livro, nesse programa não haveria mediadores, a criança seria a dona do livro. A posse do livro, realmente, foi o que me incitou a investigá-lo. Que condições de apropriação da leitura literária a posse do livro e a inserção do livro no meio familiar possibilitavam? Essa inserção alterava, ou não, as práticas de leitura dessas famílias? Ou a posse do livro seria apenas um fetiche, como nos alerta Edmir Perrotti (1999)? ${ }^{3}$

Essas questões me levaram a quatro famílias de uma escola cujos alunos receberam esses livros. A análise das práticas de leitura dessas famílias constitui o cerne deste artigo.

\section{O PERCURSO CONCEITUAL}

A discussão teórica que demarca o percurso conceitual da análise aqui empreendida define-se, em primeiro lugar, nas perspectivas discursiva e 
sociocultural da linguagem; em segundo lugar, por uma escala de observação pautada na microanálise; e, por fim, nos conceitos "disponibilidade, acesso e apropriação”, que possibilitaram à análise articular políticas e práticas.

A perspectiva sociocultural da linguagem redefine o papel e o estatuto dos leitores e de suas práticas de leitura e escrita. Essa perspectiva afirma que é impossível desconsiderar o sujeito e seu mundo de cultura ao considerar a escrita como um bem positivo em si mesmo. O reconhecimento da intrínseca e constitutiva relação da linguagem com o mundo social é uma das grandes contribuições dos estudos no campo da linguagem nas últimas décadas.

Nessa lógica, a escrita, considerada como uma prática cultural (CHARTIER, 1999), se realiza em um espaço intersubjetivo, conformado historicamente, no qual os leitores compartilham dispositivos, comportamentos, atitudes e significados culturais em torno do ato de ler (ROCKWELL, 2001).

Com relação às escalas possíveis de análise, segundo Darton (1995), os estudos históricos relacionados ao leitor e à leitura se dividem em dois: uns centrados em uma análise macro e outros em uma microanálise.

No Brasil, apenas nas últimas décadas começaram a aparecer estudos macroanalíticos que buscam retratar, de forma ampla, o perfil leitor de nosso país ${ }^{4}$ Entretanto, Darton (1995) faz várias críticas à macroanálise, sobretudo por se pautar geralmente em categorias vagas. Já Dionísio (2000) critica essa perspectiva, porque ela geralmente se restringe a medir, de forma literal, o leitor, pela quantidade de livros que diz ler, e os países, pela média de livros lidos pelos seus cidadãos. Segundo a autora, nos debates relacionados à quantidade de leitores, desconsideram-se as novas exigências sociais que envolvem a cultura escrita, reveladas em estudos sobre o letramento, que põem entre aspas, inclusive, a alusão apenas a livros quando se estuda a relação do leitor com a cultura escrita.

Em contraposição à abrangência das pesquisas macro, Darton (1995) explicita o foco na precisão característica da microanálise, embora o risco dessa perspectiva, segundo o autor, seja passar para o outro extremo definido por um "detalhismo excessivo". Diferentemente das pesquisas que traçam um perfil geral e anônimo, por mais que se cruzem os dados, a vantagem da perspectiva micro é permitir, assumindo-se o risco colocado por Darton (1995, p. 152), “ligar o 'que' com o ‘quem’ da leitura”, ou seja, compreender os eventos, práticas e protocolos ${ }^{5}$ de leitura, num espaço ou 
contexto circunscrito, de forma que possamos interligar os dados sobre o que se lê com as características subjetivas sobre quem lê, explicitando as condições de produção da leitura relacionadas aos objetivos, finalidades e gestos de leitura.

Entretanto, há também nesse estudo a necessidade de articular políticas e práticas, o que nos leva a utilizar, com conotações em pouco diferenciadas, os conceitos sistematizados por Judith Kalman (2004a, b) disponibilidade, acesso e apropriação. Dessa forma, trabalhamos, neste estudo, com os atos e práticas dos sujeitos leitores, mas também com as formas de circulação do livro nas famílias, sobretudo aqueles que vieram de políticas e programas de promoção da leitura. Faz-se necessário, então, explicitar essas diferenças ou adaptações.

Nos estudos de Judith Kalman (2003, 2004a, b), o conceito de disponibilidade refere-se às condições materiais para a prática da leitura e da escrita, definidas, principalmente, pelos lugares, ou seja, pela infraestrutura que viabiliza a distribuição de materiais impressos. Nesse sentido, ela analisa as bibliotecas, os pontos de venda de livros, revistas e jornais e os serviços de correios, entre outros (KALMAN, 2003, p. 73). No presente estudo, propomos que esse conceito articule políticas e práticas de leitura, porque o Estado, em suas diferentes instâncias, federal, estadual e municipal, busca assumir a disponibilização dos materiais impressos, ou seja, a infraestrutura necessária para viabilizar e potencializar as práticas, eventos e atos de leitura. Assim o faz, ou tenta, por meio de uma série de ações de promoção da leitura que se concretizam em diferentes programas, tanto no campo da cultura como no da educação.

Sendo assim, por um lado, a disponibilização de materiais impressos passa por políticas de promoção da leitura que envolvem a distribuição e a circulação desses materiais, seja por meio do barateamento do custo para o consumidor, seja pela construção ou consolidação de bibliotecas públicas ou particulares, seja, ainda, pelos programas e práticas escolares ou sociais que envolvam a distribuição de livros, visando à difusão da leitura e à formação de novos leitores. Por outro lado, a disponibilização também se refere às diferentes formas de aquisição do material impresso pelas famílias, nas quais se incluem as relacionadas às políticas de promoção da leitura descritas anteriormente, mas, também, outras formas mais inusitadas de obtenção de material impresso pelos sujeitos leitores. 
Dessa forma, buscamos entender se persiste ou não, na atualidade, a afirmação de Magda Soares (1995, p. 25) de que “[...] ao povo permite-se que aprenda a ler, não se lhe permite que se torne leitor." Com essa frase, a autora denunciava, na época, que, depois da alfabetização, as barreiras ao acesso à leitura se concretizavam tanto por mecanismos de sonegação de material escrito quanto por "mecanismos de distribuição seletiva desse material” (SOARES, 1995, p. 25), de forma desigual para as diferentes camadas da sociedade.

A disponibilidade de materiais impressos influencia o surgimento de oportunidades para acessar as práticas de leitura e escrita. Porém, é consenso entre os diferentes autores que a presença física de materiais impressos não é suficiente para definir as relações com a cultura escrita (BARKER; ESCARPIT, 1975; KALMAN, 2003; PERROT'TI, 1999).

É nessa dimensão, então, que o acesso está associado às condições sociais para o uso e a apropriação da cultura escrita, ou seja, o "[...] acesso refere-se às oportunidades de participar de eventos da língua escrita (situações em que o sujeito se posiciona frente a outros leitores e escritores) e às oportunidades para aprender a ler e a escrever" (KALMAN, 2003, p. 73). Dessa forma, o acesso refere-se aos meios e modalidades de apropriação da escrita, imersos em posicionamentos de poder sobre quem lê e escreve, o que se lê e escreve, quem decide sobre o que ler e escrever e, por fim, também, sobre quem define as convenções normativas e exerce poder por meio da língua escrita (KALMAN, 2004b). É a partir dessas relações de poder que as desigualdades referentes ao acesso à cultura escrita constituem-se, reconfiguram-se, acentuam-se ou diminuem, tendo como ponto de partida uma série de fatores e fenômenos sociais.

Destacamos, no universo discursivo das famílias pesquisadas, algumas categorias que nos permitem vislumbrar as diferentes oportunidades de acesso à escrita. Na primeira dessas categorias, buscamos compreender as trajetórias escolares dos sujeitos, marcadas por êxitos, limitações e frustrações em sua relação com a cultura escolar, de forma geral, e com a cultura escrita, em particular. Assim, os sujeitos explicitaram processos de alfabetização, suas memórias de leitura, a relação com professores e colegas e, em alguns casos, questões que levaram à interrupção da trajetória escolar. Em outra categoria, estão as vivências e experiências em torno dos espaços públicos de leitura, predominantemente as bibliotecas escolares. Por fim, 
sendo a disponibilidade apenas uma possibilidade e o acesso um caminho possível, é no processo de apropriação que se concretiza o momento efetivo de encontro entre o leitor e o livro.

Roger Chartier (2001, p. 116-117) utiliza o conceito de apropriação para delimitar o espaço simbólico do leitor situado entre liberdades e limitações. Ou seja, ele define esse conceito, articulando diferentes perspectivas conceituais, de forma a considerar que a apropriação seria

[...] fazer algo com o que se recebe, no sentido da pluralidade de usos, da multiplicidade de interpretações, da diversidade de compreensão dos textos, no sentido da hermenêutica, mas considerando esse fenômeno com um conteúdo sócio-histórico particular de forma a não tratá-lo como universal, invariável ou abstrato.

Segundo Chartier (2001, p. 32), no processo de leitura, deve-se considerar "a materialidade do texto e a corporeidade do leitor". Essa corporeidade refere-se tanto a seu aspecto físico quanto, principalmente, a uma corporeidade social e culturalmente construída. É seguindo essa linha que o autor afirma a necessidade de "dar uma realidade sociocultural ao leitor" (CHARTIER, 2001, p. 32), considerando-o parte de uma comunidade de interpretação, ou seja, o leitor constitui-se com relação às suas capacidades e experiências de leitura e pelas regras, convenções e códigos de leitura próprios a cada uma dessas comunidades.

Mas circunscrever a comunidade de um leitor, na sociedade atual, não é uma tarefa simples. O leitor pode estar inserido em uma rede complexa de espaços, práticas, representações e instituições de leitura e de promoção da leitura. Para Chartier (1999, p. 92), o princípio que vai reger esse recorte com relação à comunidade de leitores é instável e variável, cuja fragmentação, nos séculos XIX ou XX, “[...] resulta das divisões entre as classes, dos processos diferentes de aprendizagem, das escolaridades mais ou menos longas, do domínio mais ou menos seguro da cultura escrita." Além disso, segundo o autor, essas comunidades podem se justificar pela oposição entre cidade e campo ou entre gerações.

Nesse terreno incerto e movediço, o trabalho de investigação pressupõe, a partir dos próprios leitores, expor, sobretudo, as representações de leitor e de leitura presentes nas famílias entrevistadas, para, então, num 
processo de circularidade, compreender como se organizam as práticas de leitura e escrita, circunscritas, elas próprias, por esses modelos culturais.

Nessa perspectiva, buscou-se, então, entender, sob o ponto de vista do sujeito empírico, leitor ou não, como os conceitos de leitura e leitor ganham sentido e significado para aquele grupo ou comunidade. Ou seja, não há uma definição a priori do que venha a ser leitor, suas características e protocolos de leitura. Quem responde às questões, como quem lê e quem não lê, quem são os leitores e os não leitores, e o que os define, dessa forma, e não de outra, são os próprios sujeitos da pesquisa.

\section{AS FAMÍLIAS E SUAS CARACTERÍSTICAS}

A importância da família nos processos de constituição do babitus ${ }^{7}$ (BOURDIEU, 1989) que conformam representações e práticas de leitura (CHARTIER, 1985, 1999) há muito vem sendo estudada. Considerar a família como o contexto privilegiado da pesquisa, entretanto, não significa desconsiderar outros contextos de formação, mediação ou difusão da escrita. Considera-se que:

[...] a família é uma questão ontológica para os pobres. Sua importância não é funcional, seu valor não é meramente instrumental, mas se refere à sua identidade de ser social e constitui a referência simbólica que estrutura sua explicação do mundo (SARTI, 2005, p. 52-53).

Entender a família como referência simbólica da identidade social da pessoa pressupõe, no campo da leitura, que também as práticas leitoras se constituem em função das disposições, ou habitus, que definem práticas e representações do que é ser leitor, do que deve ou não deve ser lido, com que objetivos e em que situações é possível ou necessário ler.

É a partir dessa constatação que se ancora a hipótese de trabalho que orienta o estudo sobre as famílias, na qual se afirma que os livros do programa "Literatura em minha casa" chegam até elas revestidos por diferentes representações sobre o que é ser leitor. Essas representações, entretanto, geralmente se confrontam com outras socialmente construídas nesse contexto. Dessa forma, um discurso sobre a necessidade da formação de leitores e sobre os benefícios da leitura parece se confrontar com práticas 
diferenciadas que vão desde a negação da leitura como necessidade social a uma adesão acrítica ao escrito (GNERRE, 1994).

Nas famílias, buscou-se compreender quais livros fazem parte da vida delas, incluindo aqueles recebidos por meio do programa "Literatura em minha casa"; como esses livros chegam às casas e onde são guardados; as representações de leitura e de leitor a partir de questões como: quem são os leitores e os não leitores e o que os caracteriza; quais são as condições sociais que essas pessoas tiveram para se relacionar com a cultura escrita, ou seja, como se caracterizou seu processo de alfabetização e trajetória escolar e suas relações com bibliotecas ou outros espaços de leitura; e, por fim, compreender se e como os integrantes da família, ou outras pessoas da convivência delas, se apropriaram desses livros.

Pautados nas interações dos meios familiar e social, os sujeitos vão traçando o percurso em que se forjaram suas experiências com a cultura escrita, experiências essas fortemente relacionadas ao contexto escolar a partir de suas memórias e/ou práticas atuais de leitura. Ao mesmo tempo em que essas questões vão sendo tematizadas, analisamos a procedência dos materiais de leitura que as famílias possuem em casa e os processos envolvidos na apropriação desse material, sobretudo os livros literários. Vejamos resumidamente cada uma dessas famílias.

\section{DIOGO E SUA FAMÍLIA}

Na família de Diogo, as práticas de leitura eram modeladas pela inserção religiosa de seus membros na Igreja Universal do Reino de Deus. A Bíblia, as coleções bíblicas e os livros religiosos, comprados, doados ou emprestados, compõem grande parte do patrimônio escrito, sobretudo o livresco encontrado na casa.

$\mathrm{Na}$ família, era Poliana, irmã de Diogo, quem lia e gostava de ler textos literários, de preferência os romances que tinham histórias de amor. Em fase de vestibular, suas leituras estavam, predominantemente, ligadas à escola. Talvez, por esse motivo, a dificuldade de se lembrar dos textos, pois, como as matérias escolares, o conteúdo dos livros era esquecido depois das provas. 
Para essa família, ser leitor significava "gostar de ler", com uma ênfase colocada mais em um sentimento do que em práticas efetivas de leitura. As motivações das práticas de leitura e escrita efetivamente vivenciadas na família estavam intimamente ligadas a objetivos e necessidades religiosas e escolares.

\section{BEATRIZ E SUA FAMÍLIA}

A quase totalidade dos livros e materiais de leitura que circulavam na família de Beatriz foi adquirida por meio de doações de três diferentes fontes: a escolar - incluindo-se, aí, os livros do programa "Literatura em minha casa" -, a religiosa e uma terceira, difícil de definir, pois, embora fosse ligada ao trabalho do pai, pode, também, ser considerada uma fonte ligada ao lixo cultural de determinados grupos sociais, porque o pai, com sua carroça, os recolhia no lixo de bairros vizinhos mais abastados.

$\mathrm{Na}$ casa de Beatriz, sobressaía-se o lugar de destaque, na estante da sala, onde se guardava grande parte dos livros encontrados na casa. Nessa estante, havia duas coleções do programa "Literatura em minha casa", uma de $4^{a}$ e outra de $8^{a}$ série, recebidas por Beatriz e por Ana Paula, respectivamente.

Quanto às leituras, Ana Paula, uma das duas irmãs da Beatriz, era quem possuía o estatuto de leitora, por sua característica quase obsessiva de ler "tudo". Mesmo a outra irmã sendo uma leitora de romances, para a família isso era considerado pouco. Além disso, embora a família não fizesse esse tipo de comparação, com relação às competências leitoras, Ana Paula também possuía um processo de compreensão do lido diferenciado do da irmã Natália. Além da necessidade da imagem para o processo de compreensão do lido nas leituras de Natália, a diferença entre as duas leitoras, que nos pareceu mais significativa, é que, durante a leitura, Natália costumava esquecer o que lia, ou seja, no final do livro ela já não se lembrava do início, o mesmo não ocorria com Ana Paula, que "ia lendo e usando a imaginação". Essas características marcam uma divergência profunda entre a relação que Natália e Ana Paula estabeleciam com os romances que liam, o que aponta para formas diferentes de apropriação do texto. Ser leitor, então, para essa família, era ler tudo: livros, jornais, revistas, o que e onde houvesse escrita. 


\section{TADEU E SUA FAMÍLIA}

Embora a família tivesse uma série de livros na casa, a relação com eles era de pouca intimidade. Ao abrir um dos livros, por exemplo, encontramos uma marcação de leitura e perguntamos se alguém o estava lendo. A mãe respondeu rapidamente: Não, tá não, isso é coincidência. Todos os livros encontravam-se guardados em diferentes espaços. Nem a família sabia quais ou quantos livros havia na casa.

A mãe, a todo instante, se voltava para as memórias de leitura e reafirmava que, naquele momento, não tinha mais o hábito de ler, com frases como: Infelizmente, eu perdi toda a mania de ler. Quando era jovem, eu gostava de ler, mas hoje em dia me cansa, sabe? Me dói, assim. Mas era muito marcante, em suas falas, a importância que ela atribuía ao estudo, de uma forma geral, e à leitura, em particular. Se eu ver na mochila dele, en cobro dele pra ler, porque a leitura, ela é... ela é muito boa pra pessoa. Recorrentemente, Tadeu reclamava da imposição da leitura de livros, que, talvez pela própria imposição, ele não considerasse como livros de seu agrado.

Em síntese, na família de Tadeu, os livros foram surgindo sem que a mesma identificasse, de forma segura, suas procedências. Livros em inglês, livros de artes que ninguém sabia ao certo de onde vinham. Entre esses livros, apenas um fazia parte do programa "Literatura em minha casa", o de poesias. Ninguém soube informar o que foi feito dos outros livros da coleção. O restante dos livros encontrados na casa, ao que parece, seria jogado fora, e não foi, pois livro não se joga fora. Essa era uma afirmação constante da mãe de Tadeu.

Porém, embora nenhum dos membros se considerasse, ou fosse considerado, pela família, como leitor, o vizinho, amigo de Tadeu, que o esperava, num dos dias da entrevista, se mostrou como alguém que lia muito, surpreendendo o próprio amigo. Essa revelação abriu as portas para uma comunidade leitora, formada por jovens e adolescentes do sexo masculino, que têm os livros de aventura, de suspense e de mistério como preferência de leitura, mas também não se consideram leitores.

\section{NAIARA E SUA FAMÍLIA}

Na casa da Naiara, entre os livros da casa, encontrava-se uma grande quantidade de livros do kit da Prefeitura Municipal de Belo Horizonte ${ }^{8}$, pois, 
além da própria Naiara, mais dois irmãos estudavam na mesma rede pública em que era feita a distribuição desses livros. Todos os livros eram guardados na estante da sala. Embora houvesse alguns títulos diferentes, como os dos livros espíritas que a mãe lia, Naiara resumiu bem a procedência da grande maioria dos livros que estavam na casa, pois, segundo ela, a gente não compra livro, então deve ser tudo da Prefeitura.

Naiara dizia gostar de ler de tudo, mas aos poucos foi definindo suas preferências de leitura, baseada em dois fatores. O primeiro é que o livro, ou a revista, precisava ter gravuras, desenhos, imagens, porque senão como é que cê vai imaginar?, ou seja, as ilustrações, para ela, eram fundamentais para a compreensão do lido. O outro fator que definia as preferências de leitura de Naiara estava associado ao conteúdo do que é lido, pois, para ela, precisava haver uma relação com o vivido, com a atualidade, com a sua realidade; segundo ela, com a verdade. Ela parece associar a leitura ficcional a uma leitura chata: ficar vendo palavras, ah, e palavras que às vezes nem existem, nem é verdade. Sem o cumprimento radical de tais exigências, a leitura se inviabilizava.

Um dos irmãos também gostava de ler, mas fazia leituras esporádicas, assim como a mãe, que possuía uma rede de amigos, na qual circulavam, entre doações e empréstimos, livros de autoajuda ou de cunho espiritual.

Mas era o computador o grande favorito nas práticas de e com a leitura. A internet apareceu, ainda, no início da entrevista, quando Naiara disse ter começado a ler o livro Marambaia, mas não ter terminado, porque a internet não deixa. E afirmou: A única coisa que eu leio é recado no Orkut.

\section{LIVROS QUE ANDAM: A DISPONIBILIDADE DO MATERIAL IMPRESSO NAS FAMÍLIAS}

Sob a perspectiva da disponibilidade, analisamos, sobretudo, a relação entre a procedência dos livros e os diferentes gêneros textuais que compõem os livros que foram encontrados nas bibliotecas particulares dessas famílias e o processo de seleção dos mesmos.

A relação entre o tipo de livro ou gênero textual encontrado nas famílias está intimamente ligada à procedência dos livros. Em todas as famílias, a maior parte dos livros não é comprada nem emprestada em 
bibliotecas ou salas de leituras. Eles percorreram caminhos tanto oficiais como extraoficiais para chegar até a família.

Martine Poulain (1987, p. 408 apud DIAS, 1999, p. 130-131) compreende o patrimônio livresco da família a partir de três fontes: a primeira refere-se à compra no mercado, ou seja, à compra em um espaço de venda; a segunda ao empréstimo particular, à rede particular e informal de trocas de livros; e a terceira ao abastecimento público fora do mercado, ao empréstimo em uma biblioteca.

A partir da caracterização de Poulain, organizamos os livros encontrados nas famílias pesquisadas.

Nas casas de Beatriz, Tadeu e Naiara, a grande maioria dos livros veio dos programas de promoção da leitura, tanto o da Prefeitura como o "Literatura em minha casa". Apenas na casa de Diogo, onde não foram encontrados livros do programa "Literatura em minha casa", é que a maioria foi comprada. Vale salientar que todos os livros comprados pelo pai de Diogo, em duas coleções, e o único comprado pela mãe de Naiara são de um mercado específico, especializado em livros e matérias de leitura de cunho religioso. Mesmo assim, a compra de livros, então, não foi a forma privilegiada da chegada de livros a essas famílias. Naiara resume a questão quando diz que a gente não compra livro, então deve ser tudo da Prefeitura.

Ao mapearmos a circulação de livros, podemos dizer que os materiais de leitura, sobretudo os livros disponibilizados nas famílias, procediam de três origens principais: a escola (incluindo os livros didáticos e os livros do programa "Literatura em minha casa"), a igreja (livros comprados ou doados, panfletos e jornais) e as doações de materiais (jornais, revistas, catálogo de editores e livros diversos) que estavam a caminho do lixo.

Entre os livros que chegaram às famílias pela escola, estavam aqueles do programa "Literatura em minha casa", os que vinham todo ano na mochila doada pela Prefeitura e, ainda, dois livros encontrados na casa de Naiara referentes a projetos desenvolvidos na escola. Na casa de Beatriz, os livros do programa "Literatura em minha casa" foram encontrados em maior número (nove), pois a menina recebeu livros endereçados a alunos da $4^{a}$ série e a irmã, Ana Paula, os livros da $8^{a}$ série. Já na casa de Naiara, eram os livros doados pela Prefeitura (20) que sustentavam a biblioteca da família, pois os três filhos da casa estudavam na mesma escola pública e recebiam livros todo ano. 
Mesmo assim, é possível admitir que muitos dos livros que tinham vindo da escola, a partir dos programas de promoção da leitura, estivessem circulando em outras casas, por entre outros leitores, pois os livros do programa "Literatura em minha casa" não foram encontrados na casa de Diogo e de Tadeu, que, para surpresa da mãe deste, achou apenas um deles: Cadê os companheiros dele?, perguntou ela. Não faz muito sentido imaginar que esses livros tenham sido jogados fora, uma vez que essa não era uma prática da família, que guardava, inclusive, livros vindos de outras casas e que nunca foram lidos.

Entre os de origem religiosa, como já foi dito, estavam todos os livros que foram comprados pelas famílias: na casa de Diogo, as coleções bíblicas e, na casa de Naiara, um livro de Salmos. A íntima relação do pai de Diogo com uma instituição religiosa, desde sua época de menino órfão até o trabalho, em uma faculdade religiosa, justificava o investimento, feito por ele, na compra das coleções, cada uma com 11 pequenos livros, e, também, a quantidade de livros religiosos que chegavam à casa, doados pela faculdade ou por pessoas ligadas à igreja. Na casa de Naiara, a preferência da mãe era por livros espíritas, psicografados, e suas leituras eram mantidas por uma rede de amigos leitores, que faziam circular esse tipo de material. Nas casas de Beatriz e de Tadeu, fora o jornal da Igreja Universal, não foram encontrados, de forma significativa, outros materiais de leitura, sobretudo livros, dessa procedência.

As doações eram outra fonte importante para se entender a circulação dos livros nessas famílias. Entre essas, havia aquelas vindas do trabalho do pai de cada família (casas de Diogo e de Beatriz) e as doações precisas e imprecisas de amigos, patrões e parentes. Fora as doações feitas para a casa de Naiara, havia uma característica em comum entre as doações nas outras três famílias, embora fosse mais explícita nas casas de Beatriz e de Tadeu. Grande parte dos livros doados, nas casas de Diogo e de Tadeu, era de livros que estavam a caminho do lixo, ou seja, eles foram doados para não serem jogados fora. Já na casa de Beatriz, o pai, literalmente, recolhia do lixo os livros que trazia para os filhos. É possível afirmar que essas doações provinham do lixo cultural de outros grupos?

Sob o ponto de vista das famílias pesquisadas, não havia nenhuma hierarquia valorativa entre os livros do programa "Literatura em minha casa" ou os da Prefeitura Municipal de Belo Horizonte e aqueles doados 
pela igreja ou comprados em função de seu conteúdo religioso, ou, ainda, os que vieram do suposto "lixo cultural". Natália fez uma comparação extremamente significativa ao afirmar que ela continuaria lendo mesmo que não houvesse na casa os livros provenientes da escola, mais livros antigos, mas leria, uma vez que, para ela, fora o fato de serem novos ou antigos, a única diferença entre os livros da escola e os que o pai trazia era o público a ser atingido: adultos ou crianças.

Várias questões mostram-se intrigantes considerando-se a análise das diferentes procedências. Por exemplo, é possível perguntar se apenas as doações podem ser vistas como uma fonte, com possibilidades de subverter algum tipo de imposição cultural, uma vez que a escola e a igreja, historicamente, disseminaram e censuraram livros e leitura de acordo com seus interesses e ideologias. Sendo assim, não podemos deixar de recordar, neste ponto, a metáfora do ladrão utilizada por Larrosa (2003, p. 109) ao falar do leitor: "Não será o leitor também um ladrão, alguém que se apropria do que é impróprio, para fazê-lo sua propriedade que leva inscrita a marca de sua impropriedade primeira e da força com a qual foi apropriada?"

É importante considerar que a seleção do que se guarda e do que se joga fora, em matéria de leitura, possivelmente, define o que um grupo considera como bom e ruim, necessário e desnecessário etc. É a partir de um julgamento valorativo que se constitui o lixo de cada grupo. No caso dos livros, estes saem dos seus locais de origem, marcados por valores possivelmente negativos, mas ganham outros valores nessas famílias que não tinham a compra do próprio livro como possibilidade. Sem dúvida, principalmente na casa de Beatriz, o lixo de outros grupos era fonte de renda e material com amplas possibilidades de utilização.

De toda forma, independente da procedência, tanto a teoria quanto a análise dos dados, ora apresentados, demonstram que a posse do livro, ou a disponibilidade do material escrito, não traz, intrinsecamente, as condições para sua utilização, ou seja, para a apropriação da leitura por parte do leitor. É possível, então, possuir um livro sem ter acesso à sua leitura.

Entretanto, é fato, como dizem Barker e Escarpit (1975), que é impossível formar leitores sem livros. Portanto, a primeira consideração a ser feita é que os programas de promoção da leitura, seja o programa "Literatura em minha casa", seja o da Prefeitura Municipal de Belo Horizonte, ampliam o acervo literário das famílias. Os livros provenientes desses programas 
constituíam uma parte grande do acervo de livros literários nas famílias de Beatriz e de Naiara. Na casa de Diogo, onde eles não foram encontrados, ou foram encontrados em parte, os livros literários eram uma pequena minoria vinda da Prefeitura, sendo alguns religiosos, cujas narrativas bíblicas podem ser consideradas literárias. $\mathrm{Na}$ casa de Tadeu, a procedência dos livros literários também é da Prefeitura. Esse aumento da quantidade dos livros ocorreu também na casa de Naiara, com o recebimento de livros da Prefeitura pelos três irmãos que estudam na escola municipal. Apenas na casa de Beatriz a quantidade de livros literários, mesmo ampliada com o recebimento dos livros destinados aos alunos da $4^{\mathrm{a}}$ e $8^{\mathrm{a}}$ séries, equipara-se aos livros adquiridos por meio das redes particular e informal de trocas e doações, principalmente por aqueles que vieram do trabalho do pai.

Esses dados confirmam a estatística, traçada pelo Indicador Nacional de Alfabetismo Funcional - INAF (BRASIL, 2000, 2001, 2005), que revela um aumento no número dos livros que os sujeitos possuíam entre 2000 e 2005. Possivelmente, essa elevação se deva ao programa "Literatura em minha casa", que foi implantado em nível nacional no mesmo período, e a outros programas oficiais, em outros níveis governamentais, estaduais e municipais, como o kit da Prefeitura Municipal de Belo Horizonte, e outros não oficiais, que se prestaram a doar livros.

Entretanto, esses livros nem sempre estão em consonância com as preferências dos leitores, nem com as indicações dos profissionais da escola, ou seja, geralmente há um conflito instalado entre esses três sujeitos sociais: gestores das políticas, professores e alunos.

Os parâmetros para a seleção das obras em cada uma dessas instâncias são diferenciados. Para os gestores, ou especialistas, contratados por eles, um dos critérios mais considerados é a premiação em concursos literários. Para os professores, um desses critérios seria a adequação a determinadas faixas etárias ou níveis de aprendizagem. Já os leitores pautam-se em diferentes escolhas, apresentando maior ou menor grau de dependência das medições escolares (MACHADO, 2003) movimentadas, principalmente, por suas redes de relacionamento ou comunidades leitoras.

Mas, em qualquer dos casos, se por um lado é possível dizer que os sujeitos, nas famílias, tinham pouca, e em alguns momentos nenhuma, ingerência sobre o processo de seleção dos livros, por outro, fica evidente que havia uma seleção assistemática e inconsciente quanto aos livros que 
ficavam na casa e os que eram passados para outros em forma de doação ou por outras formas que nem as famílias sabiam especificar, como foi o caso dos livros do programa "Literatura em minha casa" não encontrados na casa do Tadeu.

\section{LEITURAS CAMBIANTES: AS CONDIC̣ÕES SOCIAIS DE ACESSO À CULTURA ESCRITA}

Para explicitar o acesso, ou seja, as condições sociais que interferem na relação desses sujeitos com a cultura escrita, buscamos compreender que experiências marcaram suas trajetórias escolares e sua relação com bibliotecas e outros espaços de leitura. Num primeiro momento, de forma geral, é possível afirmar que as trajetórias escolares de todos os membros das famílias, dos pais aos filhos, passavam, embora em diferentes níveis ou intensidade, por limitações, impossibilidades, frustrações ${ }^{9}$. Os pais de Diogo e de Beatriz e a mãe de Tadeu não completaram o ensino fundamental. Apenas os pais de Naiara chegaram ao segundo grau.

As mães de Diogo, de Beatriz e de Tadeu fizeram muitas críticas e reclamações quanto ao trabalho desenvolvido na escola, à relação dos professores com os alunos e, sobretudo, à forma como a escola se relaciona com elas.

Buscando estabelecer relações entre a formação dos leitores e a leitura literária na escola, podemos citar dois tipos de percursos: um, que ocorre a partir das práticas pedagógicas em sala de aula, e outro, que ocorre à margem desse processo. Como exemplo desse segundo percurso, Ana Paula, considerada na família de Beatriz como exemplo de leitora, criou uma intimidade maior com a leitura de livros literários, movida por um grande sentimento de timidez e inadequação à cultura escolar, a ponto de fazer da biblioteca o seu refúgio. O que ficou em sua memória e que a influenciou em suas práticas de leitura não foram as atividades em sala de aula, e sim a biblioteca escolar, nos momentos de fuga da menina tímida que não conseguia se relacionar com os colegas. Essa relação com a leitura, para Ana Paula, extrapolava os limites da escola, embora, na época da entrevista, ela dependesse, sobremaneira, da biblioteca escolar como fonte de materiais de leitura, uma vez que já havia lido todos os livros que se encontravam na casa. 
Mas, fora as lembranças de Ana Paula, que não remetiam a lembranças de leitura em sala de aula, em grande parte das memórias mais antigas e das experiências mais recentes dos demais entrevistados, o professor é sempre um mediador importante.

A importância de processos de mediação entre livros e leitores no processo de formação escolar parece-nos fundamental, uma vez que, e essa é mais uma consideração, os livros literários que chegam à família, seja por qual fonte for, parecem só atingir, de fato, aqueles que já trilham, de alguma forma, uma trajetória de mais intimidade com a cultura escrita e já tinham se apropriado da imaterialidade da leitura. Nesse sentido, na casa de Beatriz, todos os livros foram lidos por Ana Paula, mesmo porque, na representação de seu grupo familiar, leitor é quem lê "tudo". Por isso, Ana Paula não só leu os livros, como exerceu um processo de mediação entre eles e Beatriz, para quem ela também leu alguns.

Nas outras famílias, por diferentes razões, os livros vindos dos programas de promoção da leitura de forma geral não encontraram mediações que pudessem lhes dar um estatuto diferenciado daqueles que as representações de leitor e de leitura já apontavam. Por isso, principalmente a família de Naiara, que possui um grande acervo de livros, constituído a partir desses programas, não encontra motivações para sua leitura, a não ser naquela exceção em que um determinado livro estava em consonância direta com a sua representação de que a leitura para ser significativa precisa estar, intimamente, relacionada com as questões da sua vida.

Assim, na perspectiva da mediação, o que parece se delinear é que as políticas de promoção da leitura têm que caminhar em duas direções: uma, na perspectiva do fortalecimento do papel da escola como primordial na formação de novos leitores, ou seja, que leve os livros aos leitores; e outra, na viabilização física e simbólica de espaços coletivos, que passam pelas bibliotecas públicas, comunitárias ou mesmo escolares até as virtuais, em que os leitores constituídos em sua diversidade possam estabelecer redes discursivas de, com e sobre a leitura, que deem oportunidades múltiplas para que o leitor vá até o livro.

A primeira perspectiva se refere ao movimento de levar o leitor ao livro. Então, passa pelo fortalecimento da escola como promotora e mediadora da escrita. Abreu (2003, p. 34), ao considerar que a população já internalizou um discurso dos benefícios da leitura, defende que mais 
importante do que as campanhas de promoção da leitura é "[...] difundir o acesso à educação escolar, pois os dados [do INAF 2001] mostram uma relação direta entre escolarização e o gosto pela leitura [...]" Também Dionísio (2000) considera a escola como o contexto, se não o primeiro, pelo menos o determinante na formação de leitores. Além disso, como ficou patente nas famílias pesquisadas, as bibliotecas escolares são, em muitos casos, a única possibilidade de acesso aos livros, via empréstimo oficial.

As bibliotecas escolares são a grande fonte de busca de materiais de leitura para todos aqueles que ainda estão frequentando a escola, embora sejam alvo de várias críticas, entre elas a imposição sobre a utilização da biblioteca e sobre a escolha dos livros, má conservação e falta de atualização do acervo.

$\mathrm{Na}$ outra perspectiva, a que se refere aos leitores que já estabeleceram uma relação de maior intimidade com a escrita, fica evidente, no discurso de Ana Paula, sua dificuldade em frequentar outros espaços de leitura que não seja a biblioteca escolar, uma vez que ela não está mais inserida no sistema escolar.

A falta de bibliotecas municipais ou até comunitárias é marcante nas experiências de Ana Paula, de forma que sua vontade insaciável de ler depende dos livros que ela pede que Beatriz pegue na biblioteca da escola e dos livros que o pai recolhe. Mas o seu desejo de frequentar outras bibliotecas foi manifestado explicitamente: Nunca fui numa biblioteca sem ser de escola. As vezes, en vejo filme e vejo aquelas bibliotecas exageradas e fico doida pra ir numa dessas. Nesse desejo, transbordam os sentimentos positivos que Ana Paula traz de suas vivências nesse espaço no início de sua vida escolar.

A única biblioteca aberta ao público, que fica próxima à casa de Beatriz, pertence a uma casa de padres católicos e é chamada de "Biblioteca dos Padres”. Mas, como já foi dito, Ana Paula não se sentiu à vontade na única vez em que esteve lá, pois assustou-se com a rigidez das regras disciplinares: Apesar de que biblioteca é lugar de silêncio, né? Mas... Essas reticências precisariam ser mais bem exploradas, uma vez que pareciam recorrentes em todas as falas que apontavam a biblioteca como um lugar quase burocrático para pegar e devolver livros.

Não há referência, a não ser nas memórias de Ana Paula, à biblioteca como espaço de leitura. Talvez isso ocorra porque ainda persiste uma concepção idealizada de biblioteca, que se pauta na ideia da leitura 
apenas como uma atividade solitária, em que não se encaixam as práticas orais e coletivas de se relacionar com o escrito, que pareciam predominar em vários contextos, sobretudo na família de Beatriz, e que certamente predominam nas relações com o escrito entre crianças e adultos que ainda não sabem ler e escrever.

Segundo Chartier (1999, p. 78-79), pautada no processo civilizatório, que obriga "[...] os indivíduos a controlarem suas condutas, a censurar seus movimentos espontâneos e a reprimir seus afetos [...]”, foi instaurada a obrigatoriedade do silêncio nas bibliotecas universitárias na Idade Média Central. A ideia de comportamento a ser regulado e controlado fazia parte das exigências intensificadas sobre o comportamento e os limites morais da sociedade entre os séculos XVI e XIX.

Na periferia urbana pesquisada, a biblioteca, sobretudo a escolar, ainda é um local predominantemente de empréstimo de livros, ou de "depósito de livros", como diz Soares (2004, p. 21), e também, ao que parece, de pesquisa escolar, mas parece ser pouco utilizada como espaço de formação de leitores, ou seja, de encontro dos leitores com a leitura e com outros leitores.

\section{LEITORES À DERIVA}

Podemos observar múltiplas representações de leitura e de leitor presentes nos discursos e práticas de cada família.

Na casa de Beatriz, Ana Paula era considerada a leitora, por sua característica de leitora de "tudo". Mesmo levando-se em conta as leituras de Natália, ela não era considerada, pela família, uma leitora com a carga simbólica atribuída a Ana Paula, por ler apenas romances. Leitor é aquele que gosta de ler qualquer tipo de texto, livros, jornais, revistas. Além disso, Ana Paula mantinha comunicação com amigas, por meio de cartas e agendas, conhecia e dava opinião sobre as bibliotecas escolares que frequentou e sobre os livros que leu. A literatura, nessa família, parecia dividir-se em dois tipos: um genérico, em que cabiam todos os livros de diferentes gêneros e de diferentes instituições de promoção da leitura, e outro, mais específico, como os romances, "Os de amor", sendo esta, sem dúvida, a leitura preferencial das duas irmãs que mais liam na casa. No entanto, gostar de ler e, efetivamente, 
ler apenas esses livros não faziam Natália alcançar o mesmo status de leitora da irmã. Por outro lado, é importante considerar que, na vida escolar, foi Natália aquela que menos problemas enfrentou em sua trajetória escolar.

Na casa de Diogo, Poliana era a leitora não por sua inserção na cultura escrita, ou por características de suas práticas de leitura, mas pela representação de que leitor era quem gostava de ler, em contraponto às pessoas que não liam por não gostarem de ler. Suas práticas de leitura estavam intimamente vinculadas ao trabalho escolar. Para a família, era leitor, portanto, quem gostava de ler. Nesse sentido, o que define o leitor não é sua relação quantitativa ou qualitativa com os materiais que se prestam à leitura, mas uma disposição com relação a eles.

Assim, o mundo da leitura parecia dividir-se entre os que gostavam e os que não gostavam de ler, o que necessariamente não remetia aos que liam e aos que não liam, ou aos que liam muito, pouco ou nada. Também não parecia haver uma relação com a leitura literária especificamente, uma vez que a afirmação "gosta de ler" necessariamente não exigiria um complemento: gosta de ler o quê? Essa representação de leitura e de leitor que concebe a leitura como universal e autônoma está muito presente nos processos de escolarização da leitura (SOARES, 1999). Na casa de Diogo, os objetivos que moviam as práticas efetivas de leitura desses sujeitos eram ditados pelas instituições escolares e religiosas. Ou seja, os leitores liam em função de necessidades, ou exigências dos rituais religiosos vivenciados pela família e/ou movidos pelas exigências escolares, como provas, concursos vestibulares etc.

É interessante considerar que sendo Ana Paula a grande leitora da casa de Beatriz, o mercado editorial não gastaria um centavo para conquistá-la, por ela não ter recursos para comprar livros. Ela consumia, literalmente, as migalhas da cultura, o lixo cultural recolhido pelo seu pai em bairros mais abastados da cidade. A política cultural não a atingia. Ao passar da idade da escolaridade obrigatória, sem concluir o ensino fundamental, ela foi alijada do contato com as bibliotecas. Mas os livros do programa "Literatura em minha casa" ela já os havia lido "todos". Diferentemente das concepções que idealizam seus leitores e leitoras e seus protocolos de leitura, ela não guardava o título dos livros nem seus autores. Ela não diferenciava os autores nem os gêneros. A preferência pelo romance, pela história de amor, marcava 
não só as suas leituras, mas também as leituras de outras leitoras nas outras famílias, embora menos assíduas e frenéticas que ela.

$\mathrm{Na}$ casa de Tadeu, o discurso de um valor positivo para a leitura estava presente, o tempo todo, na fala da mãe. Ler, para ela, era estar bem informada, embora considerasse a leitura uma prática que deixou de conquistar na juventude, uma prática perdida. Essa relação, em que a leitura representa algo positivo, mas não vivenciado, se mostra a todo momento. Para a mãe, leitores são aquelas pessoas que gostam de ler; que um tren₹inho, assim, qualquer assim, sem importância pra gente, ela tá ali lendo. Faz parte do desejo dela participar dessa atividade, ter o bábito de ler a Bíblia, ler livros importantes, pois isso é bacana demais. Mas nem as práticas religiosas conseguiam fazê-la ceder ao movimento, ao ato de ler, que, para ela, se contrapunha ao seu comportamento irrequieto, que não lhe permitia ficar dez minutos sentada. A leitura, para ela, naquele momento, era um processo, literalmente doloroso, e, portanto, descartado: Tô te falando, me cansa, me cansa, eu começo a ler assim o pescoço dói, começa a me dar uma canseira, eu largo pra lá.

Essa perspectiva em que se contrapunha a leitura ao trabalho, à ação, é corroborada nas representações e práticas de Tadeu na família. Mas essa representação passou por alguma mutação diante do grupo a que se associa, o dos amigos de sua faixa etária. Nesse grupo de amigos, que nos atrevemos a circunscrever como uma comunidade leitora, formada por adolescentes do sexo masculino que haviam lido as séries de aventura como Harry Potter, Senhor dos Anéis e Angus ${ }^{10}$. Entretanto, eles não se consideram leitores. Para eles, leitor é quem lê um livro após o outro (Tadeu); Um leitor, mais ou menos, lê um livro por semana (Serginho); e Lucas acrescentou que Jennifer [uma vizinha] é leitora, porque ela lê até livro repetido, ou seja, as representações que definem um leitor passam pela intensidade da leitura, ou seja, pela quantidade de livros lidos num tempo determinado.

$\mathrm{Na}$ casa de Naiara, era ela quem definia o que era ser leitor, ou não, e o que caracterizava um bom livro. Enquanto assumia gostar de ler, como a sua mãe, e justificava a ausência de leitura do pai pela falta de tempo, acusava o irmão mais velho de não ler nada, o que, segundo ela, é horrivel. Entretanto, ao caracterizar suas preferências de leitura, pela quantidade de gravuras do livro e pelo conteúdo de veracidade que ele veiculava, ela passou também a emitir sua opinião sobre a leitura, de uma forma geral, entre seu grupo. A ênfase, e até certo ar professoral, que ela utilizava para 
dizer que ninguém quer saber de livro, não, em contraste com a importância que o computador e suas práticas de e com a leitura, o Orkut e o MSN têm em sua vida e na de seus irmãos, pareceu apontar, de certa forma, para a polêmica da substituição do livro pelo computador ao afirmar que a única coisa que eu leio é recado no Orkut.

Também na casa de Tadeu o computador era um forte concorrente das práticas relacionadas à leitura, sobretudo ao livro. Segundo a mãe, um dos problemas relacionados à leitura era o computador, que atrapalhou mais, tira as crianças e os adolescentes dos livros. Além dos jogos e dos programas relacionados à edição de fotografias, Tadeu explicita um pouco mais sobre suas atividades no computador ao ironizar as preocupações da mãe. Nesse momento, de certa forma, ele chama atenção para o fato de que a leitura que a mãe considerava de maneira abstrata, como sendo muito boa pra pessoa, também passava pelas práticas relacionadas ao computador, embora com características próprias. Por isso, ele afirma, de uma forma bem-humorada: Nossa, en leio demais. Orkut, MSN, aqueles recados difícil. Faltando letra. Difícil demais, não é Amanda? Tudo faltando letra, aquele trem é difícil demais, cê investe muita concentração.

Ou seja, Tadeu, de certa forma, estabelecia uma relação, que não era percebida pela mãe, de que as práticas de uso da escrita no computador eram práticas de leitura, embora a mudança que a máquina instala na mediação entre o leitor e a leitura seja considerada, por Chartier (1999), uma das revoluções nas práticas de leitura da humanidade, uma vez que revoluciona as estruturas do suporte material do escrito e consequentemente as maneiras de ler.

No processo de apropriação, as entrevistas apontaram que as diferentes relações com a leitura referiam-se, também, às formas de compreensão do texto, relacionadas tanto aos objetivos do leitor diante da leitura quanto às marcas, no próprio texto, que facilitariam, ou não, o processo de apreensão do lido: livros finos ou grossos, com ou sem ilustrações.

Nessa perspectiva, Poliana se destacou como uma leitora cujos objetivos e protocolos de leitura estavam, intrinsecamente, relacionados a seus objetivos escolares naquele momento. Esses objetivos estavam voltados, em específico, para o concurso vestibular, de forma que "os tentáculos da escola" ultrapassavam a definição do que era lido ao estabelecerem uma 
relação de distanciamento com o texto, em que o livro e a memória sobre ele estavam a serviço das cobranças escolares.

De forma parecida, embora não estivesse calcada nos objetivos escolares, Natália afirmava que, quando chegava ao final do livro, ela já não se lembrava do início, ou seja, enquanto Ana Paula dizia que ia lendo e imaginando coisas, tanto para Poliana quanto para Natália, e mesmo para Beatriz, a memória do que era lido, principalmente nos romances, era curta. Essa é uma característica de leitura que sobressai nas práticas, principalmente de Natália, que, ao chegar ao final do livro, não se lembrava do início, e de Poliana, cuja memória do que é lido durava o suficiente, apenas, para sair-se bem nas avaliações escolares.

Outra questão, ligada aos processos de compreensão da leitura, também aponta para uma das polêmicas que envolveu o programa "Literatura em minha casa”, a qual está relacionada à forma como esses livros eram apresentados ao leitor. Tal questão leva esta análise a considerar em que medida e de que forma o formato dos livros, sua diagramação e ilustrações seduziam os leitores, interferindo, por um lado, em suas escolhas de leitura e, por outro, em sua própria compreensão do que era lido. Os dados mostram que diferentes leitores fazem diferentes usos dos recursos visuais no ato de leitura. Se para Ana Paula e Beatriz as ilustrações não faziam diferença, para Natália e Naiara eram fundamentais para que elas pudessem entender o que estava sendo lido.

Não houve, entretanto, em nenhuma das entrevistas, alguma referência à diagramação dos livros, assim como às ilustrações, cores e tamanho, entre outras questões. Pelo contrário, uma das surpresas na casa de Beatriz foi identificar certo descaso com relação aos livros entregues no kit da Prefeitura Municipal de Belo Horizonte, que não estavam guardados na estante da sala como os outros, embora fossem livros esteticamente idênticos aos que eram vendidos no mercado livreiro aberto.

É importante lembrar que os livros do programa "Literatura em minha casa" passaram por significativas alterações no aspecto estético, havendo, inclusive, coletâneas organizadas em função do programa, ou seja, que não eram vendidas no mercado de livros aberto. Entretanto, a análise desses aspectos se, por um lado, evidencia as limitações e restrições de sua configuração estética, dentro e fora do livro, por outro, mostrou que havia livros do mercado aberto com características muito parecidas. 
Além disso, apenas Ana Paula e Lucas, amigo de Tadeu, apresentavam uma relação de intimidade com a leitura, que permitia que a grossura dos livros se colocasse como um prazer, e não como um problema ou uma tortura.

Além do exposto, uma última consideração refere-se ao fato de que leitores não se tornam leitores por um contato exclusivo com os objetos de leitura. Esse contato, para ser significativo, pressupõe uma rede discursiva que lhe dê significado, objetivo e importância. O computador, com os seus sites de relacionamento, como o Orkut e o MSN, já pressupõe, em sua própria origem, essa rede de discursividade, na qual os sujeitos se colocam com relação aos seus pares por meio da escrita.

A partir do próprio discurso dos sujeitos, alguns grupos principais de comunidades leitoras para além da família e da escola se mostraram. Um primeiro grupo foi formado por adolescentes e jovens do sexo feminino que tinham o romance como leitura predominante. O segundo, de adolescentes de sexo masculino, apresentou as leituras de aventura como determinantes em suas escolhas do que ler. Além desses, podemos citar uma comunidade de leitura, ou uma rede de leitores, sinalizada pela mãe de Naiara, que tinha o livro espírita ou o de autoajuda como motor, que, possivelmente, era formada por pessoas com a mesma faixa etária dela. A mediação da leitura nas políticas ou práticas pedagógicas passa pelo conhecimento, reconhecimento e fortalecimento das comunidades leitoras, como as explicitadas neste artigo, de forma a poder não só formar novos leitores como ampliar o universo de leitura dos que já o são.

\section{PARA FINALIZAR}

Ao confirmar que "[...] os gestos mudam segundo os tempos e lugares, os objetos lidos e as razões de ler [...]” (CHARTIER, 1999, p. 77), chegamos a uma diversidade de práticas de leitura e representações de leitor nas famílias. Isso nos leva a concluir que ainda é necessário conhecer, de forma efetiva, os diferentes perfis de leitor e suas práticas em nossa sociedade, para que as políticas de promoção da leitura possam não lhes outorgar uma forma legítima de leitura, mas reconhecer e viabilizar processos de interação entre a diversidade de formas de se apropriar da cultura escrita. 
A democratização da leitura só se faz possível pela ampliação das possibilidades que fecundam o universo cultural dos diferentes grupos e comunidades no confronto entre significações diferenciadas sobre o que é ser leitor e o que deve ser lido no âmbito das diferentes instituições. Essa ampliação não implica, de forma alguma, a substituição de modelos culturais, mas sim um conhecimento cada vez mais profundo da diversidade de práticas leitoras, considerando-as legitimamente construídas e constituintes do tecido social mais amplo. 


\section{REFERÊNCIAS}

ABREU, M. Os números da cultura. In: RIBEIRO, V. M. Letramento no Brasil: reflexões a partir do INAF 2001. São Paulo: Global, 2003. p. 33-45.

BARKER, R. E.; ESCARPIT, R. A fome de ler. Tradução de J. J. Veiga. Rio de Janeiro: Ed. da Fundação Getúlio Vargas, Instituto Nacional do Livro, 1975.

BOURDIEU, P. A reprodução. Rio de Janeiro: F. Alves, 1989.

BRASIL. Ministério da Educação. INAF - Indicador Nacional de Alfabetismo Funcional. Brasília: MEC, 2000.

BRASIL. Ministério da Educação. INAF - Indicador Nacional de Alfabetismo Funcional. Brasília: MEC, 2001.

BRASIL. Ministério da Educação. INAF - Indicador Nacional de Alfabetismo Funcional. Brasília: MEC, 2005.

CHARTIER, R. A história cultural: entre práticas e representações. Tradução de Maria Manuela Galhardo. Lisboa: Difel; Rio de Janeiro: Bertrand Brasil, 1985.

CHARTIER, R. A aventura do livro: do leitor ao navegador. São Paulo: Ed. da UNESP, Imprensa Oficial do Estado de São Paulo, 1999.

CHARTIER, R. Cultura escrita, literatura e história: conversas de Roger Chartier com Carlos Aguirre Anaya, Jesús Anaya Rosique, Daniel Goldin e Antonio Saborit. Porto Alegre: Artmed, 2001.

DARTON, R. O beijo de Lamourette: mídia, cultura e revolução. Tradução de Denise Bottmann. São Paulo: Companhia das Letras, 1995.

DIAS, V. A. C. Práticas de leitura de professoras no meio rural. 1999. 197 f. Dissertação (Mestrado)Faculdade de Educação, Universidade Federal de Minas Gerais, Belo Horizonte, 1999.

DIONÍSIO, M. L. T. A construção escolar de comunidades de leitores: leituras do manual de português. Coimbra: Almedina, 2000.

GNERRE, M. Linguagem, escrita e poder. São Paulo: Martins Fontes, 1994.

KALMAN, J. O acesso à cultura escrita: a participação social e a apropriação de conhecimentos em eventos cotidianos de leitura e escrita. In: OLIVEIRA, I. B.; PAIVA, J. (Org.). Educaşão de jovens e adultos. Rio de Janeiro. DP\&A, 2003. p. 71-100.

KALMAN, J. Saber lo que es la letra: uma experiência de lectoescritura con mujeres de Mixquic. México: Siglo Veintiuno Editores/Instituto de Educación de la UNESCO, 2004a. KALMAN, J. El estudio de la comunidad como un espacio para leer y escribir. Revista Brasileira de Educação, Rio de Janeiro, n. 26, p. 5-28, maio/jun./jul./ago. 2004b. http:// dx.doi.org/10.1590/S1413-24782004000200002

LARROSA, J. Pedagogia profana: danças, piruetas e mascaradas. 4. ed. Belo Horizonte: Autêntica, 2003.

MACHADO, M. Z. P. A literatura e suas apropriações por leitores jovens. 2003. 269 f. Tese (Doutorado em Educação)-Universidade Federal de Minas Gerais, Belo Horizonte, 2003. NOGUEIRA, M. A. Apresentação. Educação em Revista, Belo Horizonte, v. 10, p. 3-15, dez. 1989.

PERROT'TI, E. A leitura como fetiche. In: BARZOTTO, V. H. (Org.). Estado de leitura. Campinas: Mercado de Letras/Associação de Leitura do Brasil, 1999. p. 125-147. 
ROCKWELL, E. La lectura como práctica cultural: conceptos para el estudio de los libros escolares. Educação e Pesquisa, São Paulo, v. 27, n. 1, p. 11-26, jan./jun. 2001. http://dx.doi. org/10.1590/S1517-97022001000100002

SARTI, C. A. A família como espelho: um estudo sobre a moral dos pobres. 3. ed. São Paulo: Cortez, 2005.

SOARES, M. As condições sociais da leitura: uma reflexão em contraponto. In: ZILBERMAN, R.; SILVA, E. T. Leitura: perspectivas Interdisciplinares. São Paulo: Ática, 1995. p. 18-29. SOARES, M. Escolarização da leitura literária. In: EVANGELISTA, A. A. M. et al. (Org.). A escolarização da leitura literária: jogo do livro infantil e juvenil. Belo Horizonte: Autêntica, 1999. p. 17-48.

SOARES, M. Leitura e democracia cultural. In: PAIVA, A. et al. (Org.). Democratizando a leitura: pesquisas e práticas. Belo Horizonte: Ceale, Autêntica, 2004. p. 17-32.

\section{NOTAS}

${ }^{1}$ Muitas escolas não entregaram os livros aos alunos, causando muita discussão e polêmica. 2 Esse programa fez parte, nos anos de 2001 a 2003, do Plano Nacional de Biblioteca da Escola - PNBE - implementado pelo Ministério da Educação. O PNBE representa a primeira tentativa na história da leitura no Brasil de se criar uma política oficial sistêmica de incentivo à leitura.

${ }^{3}$ Foram essas as questões e as considerações que impulsionaram a realização da minha pesquisa de doutorado, realizada entre 2004 e 2008, num bairro de periferia da zona norte de Belo Horizonte.

${ }^{4}$ Entre essas pesquisas, podemos citar: Retrato da Leitura no Brasil e o Indicador Nacional de Alfabetismo Funcional - INAF.

${ }^{5}$ Utilizamos o termo protocolo de leitura, a partir da definição de Chartier (1985, p. 132), como indícios identificadores "[...] que designam e classificam os textos, criando, em relação a eles, expectativas de leitura, antecipações de compreensão."

${ }^{6}$ Essa autora analisou as práticas de letramento presentes na cidade de Mixquic no México, que circunscreviam o universo cultural de um grupo de mulheres em processo de alfabetização.

${ }^{7} \mathrm{O}$ conceito de habitus refere-se a "[...] esquemas estruturados de percepção, pensamento, ação, formados a partir dos modos de viver e de pensar das diferentes classes sociais, e que se traduzem por predisposições ou disposições duráveis em direção à ação" (NOGUEIRA, 1989, p. 3).

${ }^{8}$ Nesse kit, os alunos da rede municipal recebem, no início do ano letivo, material didático convencional, dois livros de literatura, agenda escolar e livro-brinquedo e brinquedos pedagógicos para as crianças pequenas. 
${ }^{9} \mathrm{Na}$ família de Naiara, a entrevista não possibilitou levantar as relações dos pais com a escola. 10 Angus: o príncipe Guerreiro é um dos livros de uma coleção de um escritor brasileiro chamado Orlando Paes Filho.

Recebido: 26/03/2013

Aprovado: 30/04/2013

Contato:

Universidade Federal de São João del-Rei

Rua João de Siqueira Afonso, 346, Residencial Parque dos Bandeirantes

CEP 36325.000

Tiradentes, MG

Brasil 